\title{
PROTECCIÓN DE LA FAMILIA Y ACCESO A LA JUSTICIA DE LOS MIGRANTES EN EL PERÚ
}

PROTECTION OF THE FAMILY AND ACCESS TO THE JUSTICE OF MIGRANTS IN PERU

\section{William Homer Fernández Espinoza*}

Resumen: La presente investigación tiene como objetivo analizar la normativa nacional e internacional sobre la protección del núcleo familiar cuando sus integrantes son migrantes en situación irregular, así como el derecho de acceso a la justicia de esta población en condición de vulnerabilidad. La metodología de investigación utilizada es descriptiva, el método aplicado es el inductivo y el enfoque cualitativo. Para su estudio se revisó la jurisprudencia peruana y los casos resueltos en el sistema interamericano de protección de los derechos humanos, entre otros textos relacionados sobre la temática. La estructura del trabajo comprende la descripción de la realidad problemática, el derecho de la protección constitucional de la familia frente a la migración, el nuevo enfoque de acceso a la justicia y la protección de los derechos de las personas migrantes. Finalmente, se presentan las reflexiones conclusivas del investigador, en las cuales se concluye que el Estado peruano debe salvaguardar mejor los derechos fundamentales de las personas migrantes y de su familia, en igualdad de condiciones y sin discriminación por motivos de su situación irregular en el país.

Palabras clave: Derechos humanos, acceso a la justicia, migración, unidad familiar, interés superior del niño

\footnotetext{
* Abogado y Magíster en Derecho Procesal de la Universidad de San Martín de Porres (Perú). Maestrando en Derecho de Familia e Infancia en la Universidad de Barcelona (España). Ganador de varios concursos de investigación jurídica. Mención de honor en el VII Premio Internacional Juan Larrea Holguín. williamfernandezespinoza@gmail.com
} 
Abstract: The purpose of this research is to analyze national and international regulations on the protection of the family nucleus when its members are migrants in an irregular situation, as well as the right of access to justice for this population in a vulnerable condition. The research methodology used is descriptive, the method applied is the inductive and the qualitative approach. For its study, the Peruvian jurisprudence and the cases resolved in the inter-American system for the protection of human rights were reviewed, among other related texts on the subject. The structure of the work includes the description of the problematic reality, the right of the constitutional protection of the family against migration, the new approach to access to justice and the protection of the rights of migrants. Finally, the conclusive reflections of the investigator are presented, in which it is concluded that the Peruvian State must safeguard better the fundamental rights of migrants and their family, on equal terms and without discrimination on grounds of their irregular situation in the country.

Keywords: Human Rights, Access to Justice, Migration, Family Unit, Best Interests of the Child

Sumario. I. Introducción. II. El derecho de protección a la familia frente a la migración. III. La protección integral y el interés superior del menor. IV. El nuevo enfoque de acceso a la justicia y la protección de los migrantes. V. Conclusiones. Referencias.

\section{INTRODUCCIÓN}

El mundo observó con tristeza y asombro cuando los medios de comunicación reportaron el 25 de diciembre de 2018, en el marco de las celebraciones por la llegada de la Navidad, la muerte de un niño guatemalteco de 8 años, que se encontraba bajo la custodia de las autoridades migratorias de Estados Unidos. El niño Félix Gómez Alonzo se convertía en la segunda víctima, al igual que Jakelin Caal, una niña procedente también de Guatemala, quienes murieron en circunstancias aún no esclarecidas luego de ser detenidos por los agentes fronterizos.

Ambos casos se suman a un número mayor de niñas, niños y adolescentes migrantes en situación irregular que han muerto o fueron separados de sus familias, luego de cruzar ilegalmente la frontera desde México. A éstos últimos se les vulneró su derecho a mantener comunicación permanente y contacto directo con sus progenitores. Se desconocen las cifras oficiales, pero se estima que hasta ahora son más de 2 mil 700 menores de 
edad apartados de sus seres queridos, colocándolos en ambientes aislados mientras se tramita la deportación a su país de origen.

Estos hechos han causado una fuerte alarma frente a la crisis migratoria vivida en la región, no solo de mexicanos que emigran a Estados Unidos, sino también de hondureños, guatemaltecos, salvadoreños y venezolanos, en su mayoría, que se trasladan a otros países por motivos económicos, políticos u otros, en búsqueda de un futuro mejor para ellos y sus familias.

En el Perú, la Superintendencia Nacional de Migraciones estima que en el 2018 el 15\% de las personas migrantes se encontraba en situación irregular. La cifra puede aumentar por el incremento del número de migrantes provenientes de Venezuela, por las dificultades que atraviesa ese país, agravadas en los últimos años. Y es que alrededor de dos mil migrantes venezolanos traspasan cada día la frontera peruana, pasando por Ecuador.

Hasta septiembre de 2018, se calcula que habría alrededor de $460 \mathrm{mil}$ ciudadanos venezolanos en el Perú, ubicándose como el segundo país con mayor presencia de familias migrantes venezolanas después de Colombia, que tiene un millón.

Según los datos del Centro Binacional de Atención Fronteriza (Cebaf) el $35 \%$ de ciudadanos venezolanos que ingresaron al Perú lo hicieron presentando solo su documento de identidad. Esto se debe a una resolución judicial expedida por el Quinto Juzgado Penal de Lima que ordeno anular el requisito de pasaporte para entrar al país, por el alto número de familias que ingresaban al territorio nacional. Además de que estaban exceptuados del requisito de pasaporte las mujeres gestantes, lo mismo aplicó a los menores de edad acompañados de al menos uno de sus padres y a los adultos mayores de 70 años o personas con enfermedad grave. El resto de personas ingresó al país de forma ilegal o han permanecido un mayor tiempo que el autorizado por la ley nacional, pese a que las políticas migratorias peruanas otorgan facilidades para el permiso de permanencia y extensión del mismo a los ciudadanos venezolanos ${ }^{1}$.

A lo antes señalado, debemos tener bien en claro que la persona migrante en situación irregular enfrenta distintas barreras como el idioma y la cultura, así como dificultades económicas y de explotación laboral, además de la xenofobia, entre otras formas de discriminación o violencia que puede sufrir. Sin embargo, evita ponerse en contacto con las autoridades

\footnotetext{
${ }^{1}$ Cfr. Decreto Supremo 002-2017-IN del Ministerio del Interior de 3-I-2017, por el cual se aprueban lineamientos para el otorgamiento del Permiso Temporal de Permanencia para los venezolanos, y Decreto Supremo 007-2018-IN del Ministerio del Interior de 19-VIII-2018, que modifica los Lineamientos para las personas de nacionalidad venezolana.
} 
competentes para salvaguardar sus derechos, por su situación irregular o de indocumentación, temiendo ser detenidos y deportados a su país de origen, por lo que se encuentran así en una condición de vulnerabilidad.

Esta realidad se agrava cuando hablamos de niñas, niños y adolescentes migrantes en situación irregular, porque en ellos se multiplican los factores de vulnerabilidad (v.gr. edad, ser migrante). Además a veces se le suma la discriminación por género, discapacidad, pobreza, u otras causas.

La situación jurídica irregular en la que se encuentra el migrante que no ha respetado las normas de ingreso de algún país o ha permanecido más tiempo que el autorizado, requiere de una protección especial del Estado por tres razones. Primero, porque las autoridades gubernamentales deben garantizar plenamente los derechos fundamentales de todas las personas, indistintamente de su condición particular como migrante irregular.

Segundo, porque ha de considerarse que la entrada o residencia irregular nunca constituye un delito o infracción a la ley penal, sino una falta administrativa. Una eventual detención o la privación de la libertad de esta persona migrante debe ser excepcional, durar el menor tiempo posible y debe partir de la evaluación individual de cada caso, justificándose solo cuando haya peligro inminente para la seguridad pública o exista el riesgo de elusión de algún proceso judicial o administrativo; y durante dicha detención la persona no debe sufrir malos tratos, crueles o humillantes, tortura, ni impedirse la comunicación con su familia.

Lo anterior guarda relación con lo sostenido por la Corte Interamericana de Derechos Humanos en el caso Vélez Loor vs. Panamá (2010), en el cual un ciudadano ecuatoriano fue detenido y sentenciado a una pena privativa de libertad por haber infringido las normas migratorias. Aunque posteriormente se dejó sin efecto la sanción impuesta - fue liberado y deportado a su país de origen-, durante su estancia en el centro penitenciario, alegó haber sido víctima de actos de tortura y malos tratos por los agentes estatales.

Y tercero, porque una eventual deportación e impedimento de ingresar al territorio nacional debe ceñirse a lo previsto en la ley, salvaguardando siempre las garantías formales y materiales del debido proceso, ejecutándose la medida solo cuando sea necesaria, razonable y proporcional en cada situación, sin vulnerar los derechos fundamentales de la persona migrante y los de su familia. Particularmente, no se debe apartar a los menores de edad de sus progenitores, debiéndose garantizar la protección de la unidad familiar y tener como consideración primordial el interés superior del menor.

Es trascendental que los Estados garanticen el derecho de la protección a la familia de la persona migrante en situación irregular, especialmente en 
aquellos casos en que la autoridad gubernamental inicia la deportación de uno de los integrantes del grupo familiar.

En el Perú, por ejemplo, el Tribunal Constitucional ha resuelto un caso recaído en el expediente 02744-2015-PA/TC, de 8 de noviembre de 2016, en el cual el colegiado declaró nula una resolución directoral de la Superintendencia Nacional de Migraciones por vulnerar el debido proceso migratorio sancionador de un ciudadano brasileño, además de que no se tuvo en consideración su situación personal, al estar casado con una ciudadana peruana y tener una hija nacida en el territorio nacional. Esta sentencia tuvo especial trascendencia por la protección otorgada a la familia y la consideración del interés superior de la niña que iba separarse de su padre.

El mencionado fallo es un importante precedente en el contexto actual del Perú, al igual que otras causas vistas por la Comisión Interamericana de Derechos Humanos, como el caso Wayne Smith, Hugo Armendáriz y otros vs. Estados Unidos (2010), en el cual se determinó que la política de deportación de ese país vulnera los derechos fundamentales de las personas migrantes, de sus familias y en especial de las niñas, niños y adolescentes.

En el presente ensayo se estudiarán los estándares internacionales de protección de los derechos humanos de las personas migrantes en situación irregular, así como las políticas del Estado peruano para garantizar el acceso a la justicia de esta vulnerable población.

\section{EL DERECHO DE PROTECCIÓN A LA FAMILIA FRENTE A LA MIGRACIÓN}

Según el magistrado español Luis Puig Ferriol (2002, pp. 179-180):

«No se encuentran en los textos legales un concepto jurídico de familia, seguramente porque ésta tiene unos perfiles distintos según sea la perspectiva que se adopte. Por ello, y al margen de cualquier texto legal, se puede partir de un concepto general de la familia como una comunidad de personas, en las que se encuentran progenitores y procreados y en la que pueden integrarse otras personas, sean o no convivientes, dentro de un círculo más o menos amplio, según se proyecte el concepto de familia (...)».

En el Perú, el art. 4 de la Constitución Política dispone que la comunidad y el Estado protegen a la familia, especialmente a la niña, niño y adolescente, la madre y al anciano en situación de desprotección familiar. Al respecto, al hablar del concepto constitucional de la familia, el Tribunal Constitucional dice: 
«Desde una perspectiva constitucional, debe indicarse que la familia, al ser un instituto natural, se encuentra inevitablemente a merced de los nuevos contextos sociales. Así, cambios sociales y jurídicos tales como la inclusión social y laboral de la mujer, la regulación del divorcio y su alto grado de incidencia, las grandes migraciones hacia las ciudades, entre otros aspectos, han significado un cambio en la estructura de la familia tradicional nuclear, conformada alrededor de la figura del pater familias. Consecuencia de ello es que se hayan generado familias con estructuras distintas a la tradicional, como son las surgidas de las uniones de hecho, las monopaternales o las que en doctrina se han denominado familias reconstituidas» (sentencia del expediente 09332-2006-PA/TC de 30-XI-2007, §7).

Así el instituto de la familia resulta constitucionalmente garantizado, estableciéndose la protección de la unidad familiar y de los derechos fundamentales de sus integrantes, indistintamente de su conformación.

Este marco jurídico tiene como fuente lo señalado en los diversos tratados e instrumentos internacionales de protección de los derechos humanos. Por ejemplo, el art. 16 de la Declaración Universal de los Derechos Humanos reconoce a la familia como el elemento natural y fundamental de la sociedad, al igual que lo hace el art. 17 de la Convención Americana de Derechos Humanos y el art. 23 del Pacto Interamericano de Derechos Civiles y Políticos. Este concepto también está consagrado en la Convención internacional sobre la protección de los derechos de todos los trabajadores migratorios y de sus familiares de 1990. Por tanto, podemos decir que el derecho internacional de los derechos humanos reconoce a la familia como el núcleo central de protección de las niñas, niños y adolescentes. También se reconoce el derecho del menor de edad a vivir con su familia y a no ser separados de ella (CIDH, 2013), dispuesto en el art. 9 de la Convención sobre los Derechos del Niño.

La Comisión y la Corte Interamericana ha señalado:

«En principio, la familia debe proporcionar la mejor protección de los niños contra el abuso, el descuido y la explotación. Y el Estado se halla obligado no sólo a disponer y ejecutar directamente medidas de protección de los niños, sino también a favorecer, de la manera más amplia, el desarrollo y la fortaleza del núcleo familiar» (Opinión Consultiva OC-17/2002 de 28-VIII-2002, §66).

En este contexto, hablamos del derecho de la niña, niño y adolescente a vivir en su familia y a ser cuidado y criado por sus progenitores en el seno de la misma, conforme a los términos establecidos en los arts. 5 y 18 de la Convención sobre los Derechos del Niño, acerca de la responsabilidad parental en la crianza de los hijos y el deber de los Estados de respetar el ejercicio de tales funciones como progenitores. Sobre el punto la Comisión Interamericana de Derechos Humanos sostiene: 
«La responsabilidad primaria por el bienestar del niño y el goce de sus derechos recae en sus progenitores y en los miembros de su familia de origen independientemente de la composición y la forma de constitución de ésta. A su vez, los progenitores tienen una serie de derechos y responsabilidades en el marco de las relaciones familiares de carácter paterno-filial, que deben ser respetados y garantizados por los Estados. Al respecto, la Convención sobre los Derechos del Niño señala que corresponde a los padres, o en su caso a los representantes legales, la responsabilidad primordial para la crianza y el desarrollo físico, mental, espiritual, moral y social del niño, debiendo ser su preocupación fundamental el interés superior del niño y su bienestar. La [Convención] es además precisa en establecer la obligación de los Estados consistente en prestar el apoyo y la asistencia adecuada a los padres y a las familias en el cumplimiento de sus responsabilidades parentales» (Informe sobre el derecho del niño y la niña a la familia, de 17-X-2013, §54).

De igual forma, el Código de los Niños y Adolescentes peruano recogió esta premisa señalando que: «El niño y el adolescente tienen derecho a vivir, crecer y desarrollarse en el seno de su familia (...) Los padres deben velar porque sus hijos reciban los cuidados necesarios para su adecuado desarrollo integral» (art. 8).

Para el pleno y armonioso desarrollo de la personalidad del menor, éste debe crecer en el seno de su familia, de ahí la particular incidencia de la unidad familiar. No obstante, la norma internacional también ha desarrollado los supuestos en que sea necesaria la separación del menor de edad con uno o ambos progenitores, pero ello debe ser excepcional y preferentemente temporal, con la finalidad de proteger sus derechos fundamentales y siempre en consideración primordial de su interés superior.

Así el art. 9 de la Convención sobre los Derechos del Niño enfatiza:

«Los Estados Partes respetarán el derecho del niño que esté separado de uno o de ambos padres a mantener relaciones personales y contacto directo con ambos padres de modo regular, salvo si ello es contrario al interés superior del niño (...). Cuando esa separación sea resultado de una medida adoptada por un Estado Parte, como la detención, (...) la deportación (...) de uno de los padres del niño, o de ambos, o del niño, el Estado Parte proporcionará, cuando se le pida, a los padres, al niño o, si procede, a otro familiar, información básica acerca del paradero del familiar o familiares ausentes, a no ser que ello resultase perjudicial para el bienestar del niño $(\ldots) \gg$.

\section{La Corte Interamericana de Derechos Humanos considera que:}

«[U]na de las interferencias estatales más graves es la que tiene por resultado la división de una familia. En este sentido, la separación de niños de su familia puede constituir, bajo ciertas condiciones, una violación del citado derecho de protección a la familia, pues inclusive las separaciones legales del niño de su familia biológica solo proceden si están debidamente justificadas en el interés superior del niño, son 
excepcionales y, en lo posible, temporales» (caso Fornerón e Hija vs. Argentina, del 27-IV-2012, §116).

Por lo tanto, las niñas, niños y adolescentes no podrán ser separados de sus familias, en especial de sus progenitores, sino por circunstancias particulares establecidas previamente en la ley y con la exclusiva finalidad de proteger integralmente sus derechos fundamentales.

Complementa lo señalado por la Convención sobre los Derechos del Niño y por el Código de los Niños y Adolescentes, lo dispuesto en el Decreto Legislativo 1297 y su respectivo reglamento aprobado por el Decreto Supremo 001-2018-MIMP del Ministerio de la Mujer y Poblaciones Vulnerables, que regula la protección de menores sin cuidados parentales o en riesgo de perderlos, el cual tiene como fin «garantizar el pleno ejercicio de sus derechos; priorizando su derecho a vivir, crecer y desarrollarse en el seno de su familia» (art. 1).

También ha de tenerse en consideración lo sostenido por el Tribunal Constitucional:

«[C]ualquier decisión relativa a la separación del niño de sus padres o de su familia debe ser excepcional y estar justificada por el interés superior del niño, y preferentemente será temporal, a fin de que el niño sea devuelto a sus padres tan pronto lo permitan las circunstancias.

Por tanto, este derecho se vulnera cuando por razones ajenas a la voluntad y al interés superior del niño, éste es separado de su familia, o se le impide el contacto con alguno de sus miembros (...). Ello porque, como es obvio, el niño necesita para su crecimiento y bienestar del afecto de sus familiares, especialmente de sus padres, por lo que impedírselo o negárselo sin que existan razones determinantes en función del interés superior de aquél, entorpece su crecimiento y puede suprimirle los lazos afectivos necesarios para su tranquilidad y desarrollo integral, así como generar la violación de su derecho a tener una familia» (sentencia del expediente 01817-2009PHC/TC de 7-X-2009, §§16-17).

Por consiguiente, al momento de tomar como medida la separación de la niña, niño o adolescente de sus padres, tutores o representantes —más aún cuando éstos últimos son familiares del menor-, las autoridades gubernamentales deben considerar sus circunstancias personales y en especial garantizar su interés superior. Por otro lado, también es importante que se garantice en todo procedimiento administrativo o judicial el derecho del menor a ser escuchado, cuya opinión tiene que ser expresada libremente y en sus propios términos, y a que se tenga en consideración dicha opinión, en función de su edad y madurez (cfr. art. 12 de la Convención sobre los Derechos del Niño). Sobre este último derecho Baratta explica: 
«La Convención se ocupa, en diversas normas, del niño (...) como sujeto de derecho en sentido pleno y no solamente entonces como persona incapaz representada por los adultos a los que pertenecen la competencia y el deber de cuidarlos. Esto significa, con la sola limitación sustancial debida a las fases diferentes del desarrollo de su competencia expresiva y lingüística, que el niño es respetado como portador de una percepción autónoma de sus necesidades, percepción de su situación y de la situación alrededor de él; como portador de un pensamiento, una conciencia y una religión; como sujeto del cual dependen libremente la comunicación y la asociación con otros sujetos» (Baratta, 2007, p. 20).

\section{El Comité de los Derechos del Niño ha advertido:}

«El niño tiene el "derecho de expresar su opinión libremente". "Libremente" significa que el niño puede expresar sus opiniones sin presión y puede escoger si quiere o no ejercer su derecho a ser escuchado. "Libremente" significa también que el niño no puede ser manipulado ni estar sujeto a una influencia o presión indebidas. "Libremente" es además una noción intrínsecamente ligada a la perspectiva "propia" del niño: el niño tiene el derecho a expresar sus propias opiniones y no las opiniones de los demás» (Observación General 12, de 20-VII-2009, §22).

Estos estándares internacionales fueron recogidos en el Código de los Niños y Adolescentes peruano, que señala:

«El niño y el adolescente que estuvieren en condiciones de formarse sus propios juicios tendrán derecho a expresar su opinión libremente en todos los asuntos que les afecten y por los medios que elijan, incluida la objeción de conciencia, y a que se tenga en cuenta sus opiniones en función de su edad y madurez» (art. 9).

Sumado a esto, el Comité de los Derechos del Niño (2009) exhorta a los Estados a garantizar el derecho de toda niña, niño y adolescente a ser escuchado, teniendo en cuenta su situación individual y social (ibid., §23). Se tomarán en cuenta las dificultades que ellos pueden experimentar para hacer oír su opinión, como por ejemplo su edad, grado de discapacidad, idioma o cuando se trate de menores de edad migrantes (ibid., §21), especialmente aquellos que se encuentran en situación irregular.

También es transcendental que las autoridades estatales brinden la información necesaria y de forma accesible a la niña, niño o adolescente, en su idioma materno y utilizando un lenguaje claro y sencillo, garantizando que el menor comprenda lo informado, para que pueda ejercer plenamente su derecho a ser escuchado.

El Protocolo Iberoamericano de actuación judicial para mejorar el acceso a la justicia, aprobado en la XVII edición de la Cumbre Judicial Iberoamericana (2014, p. 185), en el apartado sobre personas migrantes y sujetas de protección internacional, señala que: 
«La separación de los niños, niñas y adolescentes de su núcleo familiar únicamente debe realizarse bajo una justificación clara y con una duración temporal; tan pronto lo permitan las circunstancias, éstos o éstas deben ser devueltos a sus progenitores.

A la par del crecimiento de la migración de niños, niñas y adolescentes, ha aumentado el número de los que lo hacen sin el acompañamiento de alguna persona adulta (no acompañadas) y de los que lo hacen sin sus padres o tutores (separados). En estos casos, localizar a la familia es fundamental, a menos que el interés del niño establezca lo contrario».

En síntesis, podemos decir que debe garantizarse la preservación de la unidad familiar, en particular cuando sus miembros son migrantes y se encuentran en una situación irregular. En un escenario de deportación de cualquiera o de todos los integrantes de la familia, debe protegerse el derecho de la niña, niño o adolescente a vivir con su grupo familiar; cuando el contexto amerite la separación del menor de edad con uno o ambos padres, esta será excepcional y de forma temporal, teniendo en cuenta su situación individual como de vulnerabilidad. En todo caso se procurará que mantenga relaciones personales, comunicación permanente y contacto directo con sus progenitores, salvaguardando su interés superior y la protección de sus derechos fundamentales.

\section{LA PROTECCIÓN INTEGRAL Y EL INTERÉS SUPERIOR DEL MENOR}

La muerte de los menores de edad guatemaltecos, Félix Gómez Alonzo y Jakelin Caal, nos recuerda a Alan Kurdi, el niño de 3 años que falleció ahogado cuando su familia intentaba llegar a Grecia. Estos y muchos otros casos evidencian los peligros y la alta vulnerabilidad que sufren las niñas, niños y adolescentes al emigrar ilegalmente a otros países, solos o con sus familias. Quien se encuentra en tal situación migratoria generalmente ve vulnerado su derecho a vivir en el propio núcleo familiar.

Frente a esta realidad, la Asamblea General de las Naciones Unidas adoptó la Agenda 2030 para el desarrollo sostenible, en la que dentro del Objetivo 10 dedicado a la "reducción de las desigualdades", fija como meta 10.7 que los Estados faciliten la migración y la movilidad ordenadas, seguras, regulares y responsables de las personas, incluso mediante la aplicación de políticas migratorias planificadas y bien gestionadas. Asimismo, el Objetivo 16 dedicado a "Promover sociedades pacíficas e inclusivas para el desarrollo sostenible, facilitar el acceso a la justicia para todos y construir a todos los niveles instituciones eficaces e inclusivas que 
rindan cuentas", presenta la meta 16.3 que recomienda a los países promover el estado de derecho en los planos nacional e internacional, y garantizar la igualdad de acceso a la justicia para todos.

Al hablar sobre el interés superior del menor en el marco de la Convención sobre los Derechos del Niño, Cillero Bruñol sostiene:

«Desde el reconocimiento explícito de un catálogo de derechos, se superan las expresiones programáticas del "interés superior del niño" y es posible afirmar que el interés superior del niño es la plena satisfacción de sus derechos. El contenido del principio son los propios derechos; interés y derechos, en este caso, se identifican. Todo "interés superior" pasa a estar mediado por referirse estrictamente a lo "declarado derecho"; por su parte, sólo lo que es considerado derecho puede ser “interés superior”» (Cillero Bruñol, 2007, p.134).

Este principio rector está comprendido en el art. 3 de la Convención sobre los Derechos del Niño, por la cual todas las instituciones públicas y privadas deben tener como consideración primordial el interés superior del menor como un principio, un derecho y una norma de procedimiento (cfr. Comité de los Derechos del Niño, 2013, §6). De esta manera se garantiza su protección y cuidado frente a otros derechos e intereses de otras personas e incluso ante lo dispuesto en la propia ley que pueda vulnerar sus derechos fundamentales. Este concepto tiene sus raíces en el principio 2 de la Declaración de los Derechos del Niño y en el art. 19 de la Convención Americana de Derechos Humanos.

De estas consideraciones emerge el nuevo paradigma conocido como la doctrina de la protección integral de los derechos del niño, que obliga a los Estados a repensar profundamente el sentido de sus legislaciones sobre niñez y adolescencia, como instrumentos realmente eficaces de defensa y promoción de los derechos humanos, desplazando el esquema de la doctrina de la situación irregular (cfr. Plácido, 2015, p. 47).

En tal sentido, Mary Beloff (2004, pp. 31-33) señala que se reconoce al niño como un sujeto pleno de derechos, representando así la voluntad de los acuerdos y declaraciones de la comunidad internacional de crear nuevos estándares en relación con la condición jurídica de la infancia. Se deja atrás la idea del niño como objeto de "compasión-represión" propio del anterior paradigma tutelar (cfr. García Méndez, 1999).

El Comité de los Derechos del Niño ha señalado que:

«El objetivo del concepto de interés superior del niño es garantizar el disfrute pleno y efectivo de todos los derechos reconocidos por la Convención y el desarrollo holístico del niño (...) La plena aplicación del concepto de interés superior del niño exige adoptar un enfoque basado en los derechos, en el que colaboren todos los intervinientes, a fin de garantizar la integridad física, psicológica, moral y espiritual holísticas del niño y promover su dignidad humana» (Observación General 14, §§4-5). 


\section{Y la Corte Interamericana de Derechos Humanos sostiene:}

«Este principio regulador de la normativa de los derechos del niño se funda en la dignidad misma del ser humano, en las características propias de los niños, y en la necesidad de propiciar el desarrollo de éstos, con pleno aprovechamiento de sus potencialidades así como en la naturaleza y alcances de la Convención sobre los Derechos del Niño» (Opinión Consultiva OC-17/2002, §56).

En Perú el interés superior de la niña, niño y adolescente está desarrollado en el Código de los Niños y Adolescentes, el cual señala:

«En toda medida concerniente al niño y al adolescente que adopte el Estado a través de los Poderes Ejecutivo, Legislativo y Judicial, del Ministerio Público, los Gobiernos Regionales, Gobiernos Locales y sus demás instituciones, así como en la acción de la sociedad, se considerará el Principio del Interés Superior del Niño y del Adolescente y el respeto a sus derechos» (Título Preliminar, art. IX).

Aunque en nuestra Constitución Política no se haga mención expresa de este principio, el Tribunal Constitucional ha precisado lo siguiente:

«[C]onforme se desprende la Constitución, en todo proceso judicial en el que se deba verificar la afectación de los derechos fundamentales de niños (...), los órganos jurisdiccionales deben procurar una atención especial y prioritaria en su tramitación. En efecto, como uno de los contenidos constitucionalmente protegidos del artículo 4 de la Constitución que establece que "La comunidad y el Estado protegen especialmente al niño, al adolescente (...)", se encuentra la preservación del interés superior del niño y del adolescente como una obligación ineludible de la comunidad y principalmente del Estado» (sentencia del expediente 03744-2007PIIC/TC de 12-XI-2008, §5).

En efecto, el Tribunal Constitucional declaró que este principio rector está implícito como un deber especial de protección hacia el menor de edad, reconocido en la Convención sobre los Derechos del Niño vigente en Perú ${ }^{2}$. Más tarde el Tribunal Constitucional agregó:

«El principio del interés superior del niño se caracteriza por irradiar sus efectos de manera transversal. Así, el deber de considerar sus alcances, cada vez que se adopten decisiones que los tengan como destinatarios, comprende a toda institución privada o pública (...). Y exige de cualquiera de estos una actuación "garantista", de acuerdo con la cual cualquier decisión que involucre a un menor deba adoptarse considerando[lo] como un sujeto de derecho al que es preciso garantizar la satisfacción integral de sus derechos» (fallo del expediente 016652014-PHC/TC de 25-VIII-2015, §16).

${ }^{2}$ Lo dicho también consta en la sentencia del expediente 02132-2008-PA/TC de 9-V-2011. 
Esta actuación garantista posteriormente hizo que se apruebe la Ley 30466 el año 2016. La ley establece parámetros y garantías procesales para la consideración del interés superior del menor. Su art. 4 exige que se tome en cuenta el derecho del menor a expresar su propia opinión, así como el impacto de la decisión a tomarse en sus derechos fundamentales.

Es importante resaltar que el Reglamento de la Ley 30466, de 2018, desarrolló como elementos para la determinación y aplicación del interés superior de la niña, niño y adolescente, la preservación del entorno familiar y el mantenimiento de aquellas relaciones, indicando lo siguiente:

«En el ejercicio del derecho a mantener relaciones personales, la autoridad competente debe tener en cuenta la opinión de la niña, niño o adolescente, la calidad de las relaciones intrafamiliares, la necesidad de conservarlas, garantizando con ello su derecho a tener contacto directo con ambos padres de modo regular, salvo que afecte su desarrollo integral o bienestar» (art. 9.3).

Además, sobre la valoración del interés superior del niño que se encuentra en situación de vulnerabilidad —como lo es el migrante—, señala:

«Las autoridades competentes y los responsables de la toma de decisiones deben tener en cuenta la situación de vulnerabilidad de cada niña, niño o adolescente considerando sus características y condiciones individuales. Debe realizarse una evaluación individualizada del historial e identificación de los factores de riesgo» (art. 9.5).

En tal sentido, cuando hablamos del interés superior del menor migrante, nos referimos en términos generales a su bienestar, basado en la dignidad de todo ser humano, en las características y necesidades especiales que requieran para su adecuado desarrollo integral. Y del principio de la unidad familiar deducimos que únicamente puede separarse al menor de edad de su núcleo familiar, con una justificación clara y de manera temporal; tan pronto como las circunstancias lo permitan ellos deben ser devueltos a sus padres (cfr. Cumbre Judicial Iberoamericana, 2014, p. 183-185).

\section{EL NUEVO ENFOQUE DE ACCESO A LA JUSTICIA Y LA PROTECCIÓN DE LOS MIGRANTES}

Para Cappelleti \& Garth (1996, p. 11):

«El concepto de acceso a la justicia ha pasado por una trasformación muy importante (...) Un derecho de acceso a la protección judicial significaba esencialmente el derecho formal del quejoso a litigar o defender una reclamación. La teoría era que, aun cuando el acceso a la justicia puede ser un "derecho natural", los derechos naturales no exigían una acción estatal afirmativa para su protección». 
De mismo modo Méndez (2000, p. 17) señala:

«El tema de acceso a la justicia no es una problemática de aparición reciente. Se trata de un concepto que ha sufrido profundas transformaciones a partir de los siglos XVIII y XIX, en el sentido de pasar de ser una mera declaración de posibilidad de defensa de los derechos individuales, a una concepción que involucra el deber estatal de proporcionar un servicio público, protector no solo de los derechos individuales, sino también de los derechos colectivos caracterizados por la presencia de los intereses difusos».

El sistema universal, el art. 10 de la Declaración Universal de los Derechos Humanos reconoce el derecho que tienen las personas para ser oídas públicamente en los tribunales, para la determinación de sus derechos u obligaciones o contra cualquier acusación penal dirigida hacia ellas.

Por otro lado, la Declaración sobre los derechos humanos de los individuos que no son nacionales del país en que viven (1985), considera:

«(...) la Declaración Universal de Derechos Humanos proclama además que todo ser humano tiene derecho, en todas partes, al reconocimiento de su personalidad jurídica, que todos son iguales ante la ley y tienen, sin distinción, derecho a igual protección de la ley, y que todos tienen derecho a igual protección contra toda discriminación que infrinja esa declaración y contra toda provocación a tal discriminación» (Preámbulo, §3).

De igual manera, en el sistema interamericano el acceso a la justicia es un derecho fundamental que se reconoce a todas las personas y se exige a todos los Estados (cfr. Convención Americana de Derechos Humanos, art. 8 y 25). En tal sentido, la Comisión Interamericana de Derechos Humanos y la y Organización de los Estados Americanos (2007, §41) han señalado:

«El derecho internacional de los derechos humanos ha desarrollado estándares sobre el derecho a contar con recursos judiciales y de otra índole que resulten idóneos y efectivos para reclamar por la vulneración de los derechos fundamentales. (...) la obligación de los Estados no es sólo negativa -de no impedir el acceso a esos recursos- sino fundamentalmente positiva, de organizar el aparato institucional de modo que todos los individuos puedan acceder a esos recursos, para lo cual los Estados deben remover los obstáculos normativos, sociales o económicos que impiden o limitan la posibilidad de acceso a la justicia».

En Perú el derecho de acceso a la justicia no está contemplado literalmente en la Constitución Política. Sin embargo, el artículo 139 establece las disposiciones para garantizar la tutela jurisdiccional efectiva y las pautas para el debido proceso para todas las personas, sin ninguna forma de discriminación, y en especial para aquellas que se encuentran en condición de vulnerabilidad. La jurisprudencia constitucional es uniforme en la materia, y queda bien sintetizada en esta sentencia: 
«[El acceso a la justicia] implica la garantía de que los ciudadanos puedan acceder a los órganos jurisdiccionales para que se resuelva una situación jurídica, conflicto de derechos o presentación de reclamos en un proceso judicial. Ello no quiere decir, sin embargo, que los jueces se vean obligados a estimar las demandas que les sean presentadas sino que se dé respuesta a las mismas, ya sea estimando o desestimando la pretensión planteada, de manera razonada y ponderada (...)» (caso Anaximandro Díaz Irigoin, 2016, §5).

Esta noción de acceso a la justicia no está referida exclusivamente al acceso al servicio de justicia que brinda el Estado. Sino que este concepto ha evolucionado históricamente, con un nuevo enfoque que implica que éste es una garantía y un derecho fundamental, que tiene especial consideración cuando se habla de personas en situación de vulnerabilidad, porque a través de una atención oportuna y efectiva del Estado se impedirá la estigmatización de aquella persona, de tal manera que ella podrá desarrollar libremente su personalidad y el ejercicio pleno de sus derechos.

Cabe resaltar que el Poder Judicial peruano, con sus 34 distritos judiciales, adhirió a la implementación de las 100 Reglas de Brasilia, mediante Resolución Administrativa 266-2010-CE-PJ. Estas Reglas fueron aprobadas en la XIV edición de la Cumbre Judicial Iberoamericana de 2008, y son un importante instrumento que busca garantizar el efectivo acceso a la justicia de la población en situación de vulnerabilidad, sin ningún tipo de discriminación, englobando el conjunto de políticas, medidas, facilidades y apoyos que permitan a dichas personas el pleno goce de los servicios del sistema de justicia (cfr. Regla de Brasilia 1).

Las Reglas no se limitan a reflexionar sobre los problemas del acceso a la justicia de esta población, sino que también formulan recomendaciones para los órganos públicos y los servidores judiciales. Incluyen políticas que favorecen el acceso a la justicia de las personas en condición de vulnerabilidad, el trabajo cotidiano de los operadores judiciales y de quienes intervienen de una u otra forma en su funcionamiento.

En la cumbre llevada a cabo en Ecuador el año 2018, las 100 Reglas de Brasilia fueron actualizadas. Ahora la Regla 3 reza:

«Una persona o grupo de personas se encuentran en condición de vulnerabilidad, cuando su capacidad para prevenir, resistir o sobreponerse a un impacto que les sitúe en situación de riesgo, no está desarrollada o se encuentra limitada por circunstancias diversas, para ejercitar con plenitud ante el sistema de justicia los derechos reconocidos por el ordenamiento jurídico.

En este contexto se consideran en condición de vulnerabilidad aquellas personas quienes, por razón de su edad, género, orientación sexual e identidad de género, estado físico o mental, o por circunstancias sociales, económicas, étnicas y/o culturales, o relacionadas con sus creencias y/o prácticas religiosas, o la ausencia de estas encuentran especiales dificultades para ejercitar con plenitud ante el sistema de justicia los derechos reconocidos por el ordenamiento jurídico». 
Según esto, podemos decir que las poblaciones que se encuentran en situación de vulnerabilidad son: niñas, niños y adolescentes; adolescentes en conflicto con la ley penal, los adultos mayores; las personas con discapacidad; los pueblos indígenas; personas discriminadas y víctimas de violencia por razón del género; los privados de la libertad; las personas en situación de pobreza; las minorías, así como los desplazados internos y las personas migrantes. Sobre esto último, la Regla de Brasilia 13 agrega que «el desplazamiento de una persona fuera del territorio del Estado de su nacionalidad puede constituir una causa de vulnerabilidad, especialmente para aquellas personas en condición migratoria irregular».

La Corte Interamericana de Derechos Humanos, al tratar el tema de la condición jurídica y derechos de los migrantes indocumentados, en una opinión consultiva ha dicho:

«[L]a situación regular de una persona en un Estado no es condición necesaria para que dicho Estado respete y garantice el principio de la igualdad y no discriminación, puesto que (...) dicho principio tiene carácter fundamental y todos los Estados deben garantizarlo a sus ciudadanos y a toda persona extranjera que se encuentre en su territorio» (Opinión Consultiva OC-18/03 de 17-IX-2003, §118).

Y luego, en el caso Vélez Loor vs. Panamá, indicó:

«El debido proceso legal es un derecho que debe ser garantizado a toda persona, independientemente de su estatus migratorio. Esto implica que el Estado debe garantizar que toda persona extranjera, aun cuando fuere un migrante en situación irregular, tenga la posibilidad de hacer valer sus derechos y defender sus intereses en forma efectiva y en condiciones de igualdad procesal con otros justiciables» $(\$ 143)$.

Una cuestión a resolver es qué sucede cuando una persona emigra a otro país y en aquel lugar constituye su familia (contrae matrimonio, mantiene una relación de convivencia legalmente reconocida o tiene hijos), pero debido a que excedió el tiempo de permanencia en el territorio las autoridades inician el procedimiento administrativo correspondiente para la regulación de su situación migratoria o su expulsión del país; entonces se llega a criminalizar este contexto, llegando a vulnerarse sus derechos fundamentales y los de su familia. Al respecto, el Informe del Relator Especial sobre los derechos humanos de los migrantes de las Naciones Unidas (2012), sobre la penalización de la migración, afirma:

«[L]a entrada o residencia irregulares nunca deben considerarse delito, ya que no constituyen en sí delitos contra las personas, el patrimonio o la seguridad nacional. Es importante subrayar que los migrantes irregulares no son delincuentes en sí y no deben ser tratados como tales. (...) tipificar como delito la entrada ilegal 
en el territorio de un Estado trasciende el interés legítimo de los Estados de controlar y regular la inmigración ilegal y da lugar a detenciones innecesarias (...)» (§13). «[Se concluye que] la detención administrativa no debe aplicarse como medida punitiva en caso de infracción de las leyes y reglamentos de inmigración, ya que dicha infracción no debe considerarse delito» $(\$ 70)$.

Las Naciones Unidas, mediante resolución de la Asamblea General sobre la protección de los migrantes $(2010, \S 5)$, exhorta a los Estados a que:

«(...) respeten los derechos humanos y la dignidad intrínseca de los migrantes y pongan fin a los arrestos y detenciones de carácter arbitrario y a que, en caso necesario, examinen los períodos de detención con el fin de evitar la detención de migrantes irregulares durante períodos excesivamente largos y a que, cuando proceda, adopten medidas que no impliquen detención».

De igual forma, debemos destacar que la Corte Interamericana, a través del caso Familia Pacheco Tineo vs. Estado Plurinacional de Bolivia de 25 de noviembre de 2013, observó lo siguiente:

«En definitiva, un procedimiento que pueda resultar en la expulsión o deportación de un extranjero debe tener carácter individual, de modo que permita evaluar las circunstancias personales de cada sujeto, no debe discriminar en razón de nacionalidad, color, raza, sexo, lengua, religión, opinión política, origen social u otro estatus, y ha de observar las siguientes garantías mínimas: i) ser informado expresa y formalmente de los cargos en su contra, si los hubiere, y de los motivos de la expulsión o deportación. Esta notificación debe incluir información sobre sus derechos, tales como: a. la posibilidad de exponer las razones que lo asistan en contra de su expulsión y oponerse a los cargos en su contra; b. la posibilidad de solicitar y recibir asesoría legal, incluso a través de servicio público gratuito de ser aplicable y, de ser el caso, traducción o interpretación, así como asistencia consular, si correspondiere; ii) en caso de decisión desfavorable, debe tener derecho a someter su caso a revisión ante la autoridad competente, presentarse o hacerse representar ante ella para tal fin, y iii) la eventual expulsión solo podrá efectuarse tras una decisión fundamentada conforme a la ley y debidamente notificada» (§133).

En Perú la materia fue expuesta por el Tribunal Constitucional cuando resolvió el caso del ciudadano brasileño Jesús de Mesquita Oliviera (expediente 02744-2015-PA/TC), en el cual se presentó una demanda de amparo contra la Superintendencia Nacional de Migraciones a fin de que declare nula la resolución que impuso su salida obligatoria del país, impidiéndole regresar al territorio nacional. Se observó que ésta resolución vulneró el debido procedimiento al criminalizar su situación migratoria irregular que conllevaba su expulsión del país, así como la vulneración de su derecho fundamental de protección de la familia, porque al expulsarlo se perjudicaría gravemente el derecho de su hija de tener la compañía de su padre y, por consiguiente, su formación y desarrollo personal. Además, se 
añadió que tal sanción no reconoció como principios orientadores a la protección de la unidad familiar, ni el interés superior de la niña.

Otro caso de la Corte Interamericana es Vélez Loor vs. Panamá, donde se indicó lo siguiente:

«[E]l Estado puede otorgar un trato distinto a los migrantes documentados con respecto de los migrantes indocumentados, o entre migrantes y nacionales, siempre y cuando este trato diferencial sea razonable, objetivo, proporcional, y no lesione los derechos humanos. Por consiguiente, los Estados tienen la obligación de no introducir en su ordenamiento jurídico regulaciones discriminatorias, eliminar las regulaciones de carácter discriminatorio, combatir las prácticas de este carácter y establecer normas y otras medidas que reconozcan y aseguren la efectiva igualdad ante la ley de todas las personas» (\$248).

La norma vigente en ese entonces era el Decreto Legislativo 1236, el cual, aunque incluía en el art. V del Título Preliminar el principio de no criminalización de la migración irregular, resultaba incompatible con la Constitución Política por la «(...) falta de regulación de las garantías formales y materiales que componen el derecho al debido procedimiento extranjeros sujetos a un procedimiento migratorio sancionador» (Tribunal Constitucional, 2016, §45). También se adujo la falta del reconocimiento de los principios orientadores para la protección de la familia.

el Decreto Legislativo 1236 fue derogado por el Decreto Legislativo 1350, que es la actual Ley de Migraciones. Hoy se reconoce en los arts. V y VI del título preliminar los principios de unidad migratoria familiar y de interés superior del niño, respectivamente. El art. 64 relativo a la formalización y ejecución de las sanciones migratorias, dispone que la autoridad competente evaluará la suspensión de la ejecución de la sanción de salida obligatoria cuando se compruebe la evidente e inminente riesgo de vulneración de la unidad familiar o del interés superior del menor.

Además, recientemente se aprobó el Decreto Supremo 001-2017-IN que establece los lineamientos para el otorgamiento del permiso temporal de permanencia para las personas extranjeras madres o padres de hijas o hijos peruanos menores de edad.

Este cambio normativo surgió por las recomendaciones realizadas por la Defensoría del Pueblo (2009, pp. 192-194) a través del Informe 146, sobre Migraciones y Derechos Humanos, el cual concluyó que el Estado debía realizar una actualización normativa según las obligaciones contraídas con la suscripción de la Convención Internacional sobre la protección de los derechos de todos los trabajadores migratorios y de sus familiares, y en especial debía adecuar los conceptos de política migratoria con los estándares internacionalmente aceptados. 
Las reformas también tuvieron su origen en las observaciones formuladas por el Tribunal Constitucional (2016, §34), que precisó:

«En el ámbito específico de los niños cuyos padres tengan la condición de migrantes en situación irregular, es posible identificar dos intereses en conflicto: por un lado, la facultad del Estado de implementar su propia política migratoria para alcanzar fines legítimos que procuren el bienestar general y la vigencia de los derechos humanos, y, por otro, el derecho de la niña o del niño a la protección de la familia y, en particular, al disfrute de la vida de familia con el mantenimiento de la unidad familiar en la mayor medida posible. En consecuencia, corresponde al Estado garantizar un ejercicio legítimo y compatible de ambos bienes jurídicos, a partir de una adecuada y rigurosa ponderación entre la protección de la unidad familiar y los intereses estatales legítimos, por lo que corresponderá determinar, en el contexto de cada caso concreto, que la expulsión de uno o ambos progenitores no conlleve una injerencia abusiva o arbitraria en la vida familiar de la niña o del niño».

\section{Conclusiones}

1. Perú ha implementado políticas para afrontar los desafíos asociados a la migración actual, adoptando el Pacto Mundial para una Migración Segura, Ordenada y Regular (2018), en la conferencia intergubernamental convocada por las Naciones Unidas. Entre otras políticas destinadas a garantizar el efectivo acceso a la justicia a la población migrante.

2. Así el Poder Judicial, a través de la Resolución Administrativa 0902016-CE-PJ, aprobó el Plan Nacional de Acceso a la Justicia de Personas en Condición de Vulnerabilidad - Poder Judicial del Perú 2016-2021, para la eficacia de las 100 Reglas de Brasilia, el cual tiene como eje de trabajo 7, la protección de los derechos de los migrantes y desplazados internos, y como principal objetivo promover la articulación para promover la defensa de las personas extrajeras, particularmente aquellas que se encuentran en una situación jurídica irregular.

3. Esta política institucional guarda relación con los objetivos y metas del Plan Nacional de Acción por la Infancia y la Adolescencia 2012-2021, para la protección de los derechos fundamentales de los menores migrantes. Esto es coherente con las recomendaciones hechas por el Protocolo Iberoamericano de actuación judicial para mejorar el acceso a la justicia formulado en la Cumbre Judicial Iberoamericana (2014, p. 196), en donde resulta fundamental el derecho de la persona migrante a la información, asistencia consular, asistencia legal, defensa pública y derecho a un intérprete, cuando corresponda, y la implementación de sistemas adecuados de identificación de personas que se encuentran en situación de vulnerabilidad para asegurar que se garanticen sus derechos. 
4. Aunque existe un camino largo por recorrer, sobre todo en el sistema de justicia, podemos decir que el Estado peruano garantiza plenamente los derechos fundamentales de todas las personas, indistintamente de su condición de migrante irregular: salvaguarda el acceso a la justicia de esta población en condición de vulnerabilidad, protegiendo su libertad e integridad personal; defiende a la unidad familiar; y considera primordialmente el interés superior del menor, la situación especial en la que encuentra como migrante o su familia, su derecho a ser oído y tiene en cuenta dicha opinión por las autoridades gubernamentales, cuando se tome como medida la separación del menor de edad de su núcleo familiar (lo que sólo se puede hacer si la medida es necesaria, razonable y proporcional).

5. Finalmente, debemos resaltar que el Perú tiene una política innovadora y realiza un trabajo inédito frente a otros países de la región. Va a la vanguardia en la lucha para que la justicia y la protección de los derechos de las personas en condición de vulnerabilidad no sea una mera declaración, sino una realidad accesible y verdadera, que afronte las diversas barreras asociadas a la migración.

\section{REFERENCIAS}

Asamblea General de las Naciones Unidas (2010). Resolución de Protección de los migrantes. En: https://www.acnur.org/fileadmin/Documentos/BDL/2016/10722. pdf?file=fileadmin/Documentos/BDL/2016/10722 (último acceso 23-XII-2019).

Baratta, A. (2007). Democracia y Derechos del Niño. En Justicia y Derechos del Niño. En: http://www.unicef.cl/web/wp-content/uploads/doc_wp/justcia\%20_y_ derechos_9.pdf (último acceso 23-XII-2019).

Beloff, M. (2004). Un modelo para armar iy otro para desarmar!: protección integral de derechos del niño vs. derechos en situación irregular. En Los Derechos del Niño en el Sistema Interamericano. Buenos Aires: Editores del Puerto.

Cappelletti, M. \& Garth, B. (1996). El acceso a la justicia. México: Fondo de Cultura Económica.

Cepal (2018). La Agenda 2030 y los Objetivos de Desarrollo Sostenible. Una oportunidad para América Latina y el Caribe. En: https://repositorio.cepal.org/bitstream/ handle/11362/40155/24/S1801141_es.pdf (último acceso 23-XII-2019).

Cillero Bruñol, M. (2007). El interés superior del niño en el marco de la Convención Internacional sobre los Derechos del Niño. En Justicia y Derechos del Niño. En: http://www.unicef.cl/web/wp-content/uploads/doc_wp/justcia\%20_y_ derechos_9.pdf (último acceso 23-XII-2019).

CNN Español (18-I-2019). Se desconoce la cifra oficial de niños separados de sus padres en la frontera sur de Estados Unidos. CNN Español. En: https://cnnespanol.cnn.com/video/politica-separacion-familiar-estados-unidos- 
mexico-frontera-gobierno-trump-departamento-salud-cierre-directo-dusa-cnnee/ (último acceso 23-XII-2019).

Comisión Interamericana de Derechos Humanos \& Organización de los Estados Americanos (2013). Derecho del niño y la niña a la familia. En: https://www.oas.org/es/cidh/infancia/docs/pdf/informe-derecho-nino-a-familia.pdf (último acceso 23-XII-2019).

Comisión Interamericana de Derechos Humanos \& Organización de los Estados Americanos (2007). El acceso a la justicia como garantía de los derechos económicos, sociales y culturales. En: http://www.cidh.org/pdf\%20files/ACC ESO\%20A\%20LA\%20JUSTICIA\%20DESC.pdf (último acceso 23-XII-2019).

Comisión Interamericana de Derechos Humanos (2010). Caso 12.562 Wayne Smith, Hugo Armendáriz et al. vs. Estados Unidos. En https://www.acnur.org/fileadmin/ Documentos/BDL/2010/7959.pdf?file=fileadmin/Documentos/BDL/2010/7959 (último acceso 23-XII-2019).

Comité de los Derechos del Niño (2005). Observación General 6: Trato de los menores no acompañados y separados de su familia fuera de su país de origen. En: https://www.acnur.org/fileadmin/Documentos/BDL/2005/3886.pdf (último acceso 23-XII-2019).

Comité de los Derechos del Niño (2009). Observación General 12: El derecho del niño a ser escuchado. En: https://www.acnur.org/fileadmin/Documentos/BDL/2011 7532.pdf (último acceso 23-XII-2019).

Comité de los Derechos del Niño (2013). Observación General 14: Sobre el derecho del niño a que su interés superior sea una consideración primordial.

Consejo de Derechos Humanos de las Naciones Unidas (2012). Informe del Relator Especial sobre los derechos humanos de los migrantes. En: https://www.ohchr.org/Documents/HRBodies/HRCouncil/RegularSession/Sessi on20/A-HRC-20-24_sp.pdf (último acceso 23-XII-2019).

Corte Interamericana de Derechos Humanos (2002). Opinión Consultiva OC-17/2002. En: http://www.corteidh.or.cr/docs/opiniones/seriea_17_esp.pdf (último acceso 23XII-2019).

Corte Interamericana de Derechos Humanos (2003). Opinión Consultiva OC-18/03: Sobre la condición jurídica y derechos de los migrantes indocumentados. En: https://www.acnur.org/fileadmin/Documentos/BDL/2003/2351.pdf (último acceso 23-XII-2019).

Corte Interamericana de Derechos Humanos (2010). Caso Vélez Loor vs. Panamá. En http://www.corteidh.or.cr/docs/casos/articulos/seriec_218_esp2.pdf (último acceso 23-XII-2019).

Corte Interamericana de Derechos Humanos (2012). Caso Fornerón e hija vs. Argentina. En: http://corteidh.or.cr/docs/casos/articulos/seriec_242_esp.pdf (último acceso 23-XII-2019).

Corte Interamericana de Derechos Humanos (2013). Caso Familia Pacheco Tineo vs. Estado Pluricultural de Bolivia. En: https:/www.acnur.org/fileadmin/ Documentos/BDL/2013/9390.pdf (último acceso 23-XII-2019). 
Cumbre Judicial Iberoamericana (2008). Reglas de Brasilia sobre acceso a la justicia de las personas en condición de vulnerabilidad. En: https://www.acnur.org /fileadmin/Documentos/BDL/2009/7037.pdf (último acceso 23-XII-2019).

Cumbre Judicial Iberoamericana (2014). Protocolo Iberoamericano de acceso a la justicia para personas y grupos vulnerables. En: http:/www.cumbrejudicial.org/ productos-y-resultados/productos-axiologicos/item/38-protocolo-de-acceso-ala-justicia-para-personas-y-grupos-vulnerables (último acceso 23-XII-2019).

Cumbre Judicial Iberoamericana (2018). Propuesta de actualización de las Reglas de Brasilia. En: http://www.cumbrejudicial.org/comision-de-seguimiento-de-lasreglas-de-brasilia/documentos-comision-de-seguimiento-de-las-reglas-debrasilia/item/597-propuesta-de-actualizacion-de-las-reglas-de-brasilia (último acceso 23-XII-2019).

Defensoría del Pueblo (2009). Informe 146: Migraciones y Derechos Humanos. Supervisión de las políticas de protección de los derechos de los peruanos migrantes. En: https://www.defensoria.gob.pe/wp-contvSent/uploads/2018 /05/informe-146.pdf (último acceso 23-XII-2019).

El Comercio (16-X-2018). Venezolanos en el Perú: aumenta el número de migrantes que ingresan a diario por Tumbes. El Comercio. En: https://elcomercio.pe/peru/ tumbes/venezolanos-peru-registran-aumento-ingreso-diario-migrantes-tumbesnoticia-568012 (último acceso 23-XII-2019).

El Comercio (17-X-2018). Venezolanos sí deberán presentar pasaporte para ingresar a Perú. El Comercio. En: https://elcomercio.pe/peru/venezolanos-deberan-portarpasaporte-ingresar-peru-noticia-568274 (último acceso 23-XII-2019).

El Diario (1-IX-2017). Dos años de la muerte de Aylan: "Desde entonces todo a ido a peor para los refugiados". El Diario. En: https://www.eldiario.es/desalambre/anosmuerte-Aylan-entonces-peor_0_682081960.html (último acceso 23-XII-2019).

García Méndez, E. (1999). Infancia, ley y democracia. En Justicia y Derechos del Niño. San José: Unicef.

Méndez, J. (2000). El acceso a la justicia, un enfoque desde los derechos humanos. En José Thompson (coord.). Acceso a la Justicia y Equidad. Estudio en siete países de América Latina. San José de Costa Rica: IIDH.

Ministerio de la Mujer y Poblaciones Vulnerables (2012). Plan Nacional de Acción por la Infancia y la Adolescencia 2012-2021. En: https://www.mimp.gob.pe/ webs/mimp/pnaia/pdf/Documento_PNAIA.pdf (último acceso 23-XII-2019).

Naciones Unidas (2018). Pacto Mundial para una Migración Segura, Ordenada y Regular. Firmado en Marruecos. En: https://refugeesmigrants.un.org/sites/default/files /180713_agreed_outcome_global_compact_for_migration.pdf (último acceso 23-XII-2019).

Perú 21 (15-X-2018). Incrementa el ingreso de venezolanos al Perú tras sentencia que suspende el requisito de pasaportes. Perú 21. En: https://peru21.pe/peru/ incrementa-ingreso-venezolanos-peru-sentencia-suspende-requisito-pasaportes434596 (último acceso 23-XII-2019). 
Plácido Vilcachagua, A. (2015). Manual de derechos de los niños, niñas y adolescentes. Lima: Instituto Pacífico.

Puig Ferriol, L. (2002) Constitución y protección de la familia. En: https://dialnet. unirioja.es/descarga/articulo/1112832.pdf (último acceso 23-XII-2019).

RPP Noticias (18-XII-2018). Congresistas de EE.UU. denuncian "fallos sistemáticos" en muerte de niña guatemalteca. RPP Noticias. En: https://rpp.pe/mundo/estadosunidos/congresistas-de-eeuu-denuncian-fallos-sistematicos-en-muerte-de-ninaguatemalteca-noticia-1170426 (último acceso 23-XII-2019).

RPP Noticias (25-XII-2018). Murió un segundo niño migrante de 8 años tras ser detenido en la frontera de EE.UU. RPP Noticias. En: https://rpp.pe/mundo/estadosunidos/murio-un-segundo-nino-migrante-de-8-anos-tras-ser-detenido-en-lafrontera-de-eeuu-noticia-1171627 (último acceso 23-XII-2019).

Tribunal Constitucional (2007). Caso Reynaldo Armando Shols Pérez. En: https://tc.gob.pe /jurisprudencia/2008/09332-2006-AA.pdf (último acceso 23-XII-2019).

Tribunal Constitucional (2008). Caso José Luis Ñiquin Huatay. En: https://tc.gob.pe /jurisprudencia/2008/03744-2007-HC.pdf (último acceso 23-XII-2019).

Tribunal Constitucional (2009). Caso J.A.R.R.A. y V.R.R.A. En https://tc.gob.pe /jurisprudencia/2009/01817-2009-HC.pdf (último acceso 23-XII-2019).

Tribunal Constitucional (2011). Caso Rosa Felicita Elizabeth Martínez García. En: https://www.tc.gob.pe/jurisprudencia/2011/02132-2008-AA.html (último acceso 23-XII-2019).

Tribunal Constitucional (2015). Caso C.F.A.P. En: https://tc.gob.pe/jurisprudencia /2015/01665-2014-HC.pdf (último acceso 23-XII-2019).

Tribunal Constitucional (2016) Caso Jesús de Mesquita Oliviera et al. En: http://www.tc.gob.pe/jurisprudencia/2016/02744-2015-AA.pdf (último acceso 23-XII-2019).

Tribunal Constitucional (2016). Caso Anaximandro Díaz Irigoin. En: https://tc.gob.pe/ jurisprudencia/2017/01873-2014-AA.pdf (último acceso 23-XII-2019).

Vega Bendezú, K. (27-28-XII-2018). Pacto mundial para la migración segura, ordenada y regular: Perspectivas. En Encuentro interinstitucional por la justicia y la no violencia. Lima: Universidad de La Habana. 